\title{
Research on the Model of Autonomous Creation of College English Teaching Based on Innovation Perspective
}

\author{
Dan $\mathrm{Xu}$ \\ Faculty of International Studies, Henan Normal University, Xinxiang, China \\ Email: $x_{-}$dan@foxmail.com
}

\begin{abstract}
With China's increasing national strength, English, as an international language, has become increasingly prominent in its social role. The society puts forward new standards for college English teaching, and raises higher requirements for the training of foreign language talents. It particularly emphasizes the importance of the cultivation of comprehensive communicative competence in English language in college English teaching. This article starts with discussing the impact of college entrance examination English reform on college English education, summarizes the characteristics of research from the perspective of innovation, and clarifies the characteristics of teaching and learning modes from the perspective of innovation. From the aspect of improving the self-quality of English teachers, it seeks a breakthrough for the reform of college English teaching, and explores the way for teachers to independently create students from the perspective of innovation. Related research results can effectively improve the quality of English teachers, make English teachers have their own sense of mission and urgency, make bold innovations, and cultivate more comprehensive English talents.
\end{abstract}

Keywords: innovation perspective, college English, college students, autonomous creation

\section{Introduction}

Since the reform and opening up, with the rapid development of domestic economy, along with the acceleration of globalization, China's economic and political status in the world continues to strengthen, foreign-funded enterprises and Sino foreign cooperation projects increase, domestic and foreign exchanges are also increasingly frequent, English as an international language, its social role is increasingly prominent. The society has put forward new standards for College English teaching and higher requirements for the cultivation of foreign language talents, especially the importance of the cultivation of language communication ability in teaching. [1]

In order to adapt to the new situation of China's higher education development, deepen teaching reform, improve teaching quality, and meet the needs of the country and society for talent training in the new period. In 2007, the Teaching Requirements for College English Courses issued by the Ministry of Education pointed out that college English teaching is an organic part of higher education, and college English courses are a compulsory basic course for college students. The teaching goal of college English is to cultivate students' comprehensive English application ability, especially listening and speaking ability, so that they can communicate effectively in English in future study, work and social communication. [2] At the same time, it will strengthen its independent learning ability and improve its comprehensive cultural literacy to meet the needs of China's social development and international exchanges. College English is guided by the theory of foreign language teaching, with English language knowledge and applied skills, cross-cultural communication and learning strategies as the main content, and integrates a variety of teaching models and teaching methods into one teaching system. [3-5]

In order to further deepen the reform of undergraduate education and teaching, improve the quality of undergraduate education, and vigorously improve the level of personnel training, the Ministry of Education and the Ministry of Finance decided to continue to implement the "Quality and Teaching Reform Project of Undergraduate Education in Higher Education" (hereinafter referred to as "Undergraduate Teaching Engineering"). The purpose of the "undergraduate teaching project" is to improve the quality, which is the core task of the development of higher education, the basic requirement for building a strong country with higher education, and the key to achieving the strategic 
goal of building a strong country with human resources and an innovative country. The core of comprehensively improving the quality of higher education is to vigorously improve the level of personnel training. The fundamental task of higher education is to train talents. As an indispensable college English education and teaching of higher education, we must also comply with the requirements of the times, clearly define the training objectives, reform the training methods and teaching models, and train qualified English talents for the society.

There is no doubt that the current reform of college English education and teaching across the country has achieved certain results. However, the teaching philosophy and teaching model of traditional teaching thinking are still deeply ingrained. The graded teaching model does not change the soup, the main character of the classroom is still the teacher, and the student is in a subordinate position. Students are accustomed to passive acceptance, have limited communication with classmates and teachers in the classroom, and lack opportunities for practice, which affects students' enthusiasm for learning English and the quality of college English teaching. [6] Specifically in:

1. The teaching concept is backward, the emphasis is on knowledge transfer, and the ability training is neglected. It cannot meet the requirements of quality education in the new era.

2. The teaching mode is outdated and the teaching method is single, which cannot meet the requirements of the new teaching mode established in the computer environment in the new period.

3. The curriculum is unreasonable, focusing on reading, listening and speaking, and not adapting to the teaching goals of college English. In particular, it is necessary to cultivate students' "speaking and listening ability".

4. There is a single assessment method, which emphasizes language knowledge and light language ability, and cannot cultivate students' awareness of improving pragmatic ability in all aspects.

\section{Connotation of College English Teaching}

We are living in a technology age. It is worth noting that the development of science and technology is inseparable from the development of human reason. The development of science and technology fully shows the great power of human reason on the one hand, and it is also an important yardstick for the development of human reason on the other. It is no exaggeration to say that the history of modern western philosophy has always written two words-"rational". The word "rational" has always occupied a very important position in the history of western philosophy, and its connotation is constantly enriching and changing. Marx Weber divided rationality into instrumental rationality and value rationality. The essence that pushes science and technology forward is instrumental rationality. With the development of science and technology, the entire human life also gradually appears to be immersed in instrumental rationality. In education, the shadow of instrumental rationality can also be found everywhere. Looking at the current college English teaching in China, due to the influence of pure tool rational thinking, it shows a lot of phenomena that are not compatible with the overall development of college students. [7] Therefore, it is necessary to analyze the influence of instrumental rationality on college English teaching.

\subsection{Connotation of Teaching}

The teaching phenomenon is complicated, and its essence reveals a long process of understanding. According to archeological findings, the words "teaching" and "learning" have appeared in the Oracle bone inscriptions of the Yin and Shang dynasties. The beginning of the "learning" said: the founding of the army and civilians, teaching first. "Teaching" here has a very broad meaning and is almost a synonym for "education", which is not equivalent to what we are talking about today. "Learning" also said: learn and then know insufficient, teach and then know the difficulties. If you do not know enough, you can be reflexive; if you are poor, then you can strengthen yourself. "Teaching" here has the meanings of professor, enlightenment, and teaching. Xu Shen wrote in Shuo Wen Jie Zi: "Teach, do what works, do what works." "Shi" here means "teaching", and "effect" means learning. Later, people put too much emphasis on "exercise" and dominated "effect" with "exercise", highlighting the dominant position of "exercise". In the West, "Teaching" English means "Teaching" and "Instruction", and its basic meanings are "teaching" and "instruction". The learned English means "Learning". Therefore, the basic 
meaning of "teaching" is the same in both China and the West, and it means "teaching" and "teaching". And the word "learning" still has the basic meaning of "learning" in both the East and the West.

Mr. Wang Cesan once pointed out that "teaching" really refers to the "teaching" of teachers and the "learning" of students. In the tomb table made by Mr. Ou Yangxiu for Mr. Hu Min in the Song Dynasty, he wrote: "Mr. There are hundreds of disciples who come and go, and each teaches them by tradition; their teaching methods are the most prepared, and they have been studying the land of Southeast Asia for several years. The "teaching" mentioned here is close to what we are talking about today. But as the educator Smith said: the word teaching has been inextricably linked to learning since ancient times.

Teaching is a special interaction activity between teachers and students based on dialogue, communication, understanding and cooperation to carry on knowledge, skills and cultural heritage and create students. The activity should mainly reflect the spiritual encounter and cultural connection between teachers and students and between different cultures.

\subsection{Connotation of College English}

The term "college English" originally came from English expert Professor Hu Wenzhong's "College English" for non-professional English textbooks. It refers to English courses for non-foreign language college students, originally called public English. In November 1986, after the Public Foreign Language Teaching Research Association of China was renamed the College Foreign Language Teaching Research Association, public English was also renamed College English accordingly. Later, "College English" was gradually considered to be the English for non-foreign language students corresponding to "Professional English". It can be seen from this that college English is a compound word. First, it is a university, not a primary or secondary school. It determines that the students studying this course are college students and non-foreign language majors. Second is English. Non-foreign language undergraduate students learn not other language subjects, but English. Therefore, we define college English as a course for non-foreign language undergraduate students to improve their language knowledge, language skills and humanities.

There are many differences between college English and professional English. The main difference is first of all the nature of teaching: the nature of college English is mainly compulsory basic courses in colleges, while professional English is a professional course. The second is that the teaching goals are different: the teaching goal of college English is to train students' comprehensive English application ability, especially the listening and speaking ability, so that they can communicate effectively in English in future study, work and social communication. At the same time, it will strengthen its independent learning ability and improve its comprehensive cultural literacy to meet the needs of China's social development and international exchanges; The teaching goal of professional English is to cultivate a combination of solid English language foundation and broad cultural knowledge, and to be able to use English proficiently in foreign affairs, education, economics and trade, culture, science and technology, military and other departments for translation, teaching, management, research and other tasks. English language talent. According to this, it can be seen that the target of college English training is to build talents from all walks of life that can use English as a working tool and have cross-cultural knowledge and communication skills. The target of professional English training is to use English as a tool to work and earn a living. professional. The third is that the curriculum is different: the college English courses are mainly basic knowledge courses supplemented by partly improved courses. The academic system is usually about 250 hours in two years. The professional English courses are divided into three categories: professional skills, professional knowledge and related professional knowledge. The four-year academic year has a total of 2000-2200 hours. The fourth is that the requirements for teachers are different: college English requires teachers to be more general and rough-College English teachers need to master basic teaching theories and methods in all aspects of listening, speaking, reading, writing, and translation. Systematization requires teachers' knowledge to be more professional and in-depth.

The above major differences determine that college English must highlight basic language knowledge, skills, learning strategies and cross-cultural communication in the teaching process, thereby highlighting the instrumentality and humanity of its teaching. And professional English must highlight professional knowledge, professional skills and related professional knowledge in the teaching process, so as to highlight the professionalism of its teaching. 


\subsection{Connotation of College English Teaching}

By analyzing the concepts of teaching and college English, we believe that college English teaching is essentially a teaching activity, and that teaching activities are the most essential attribute of college English teaching; The target of college English teaching is non-foreign language undergraduates; The implementers of college English teaching are college English teachers and non-foreign language undergraduates; In terms of teaching content, the content of college English teaching is basic language knowledge, skills, cross-cultural communication and learning strategies; In terms of teaching methods, college English teaching, like other teaching, implements classroom and extracurricular teaching. It is a teacher-led, student-centered activity and an interactive activity between teachers and students; In terms of teaching purposes, college English teaching is to allow students to master basic knowledge and skills to form correct emotions, attitudes, and values. Improve their cross-cultural communication skills based on cross-cultural understanding, communication and critical skills. Improve their humanities.

Based on the above analysis of college English teaching. Our definition of college English teaching is: based on dialogue, communication, understanding and cooperation for non-foreign language undergraduates, based on foreign language teaching theories, using the English language as a carrier, and using English language knowledge and application skills. Cross-cultural communication and learning strategies are the main content of the transfer of language knowledge, skills and culture between teachers and students, and special interaction activities for students. This special communication activity takes classroom teaching as the main channel and network and non-network second classroom teaching as an extension, which reflects the spiritual encounter and cultural connection between teachers and students and between different cultures. Through this kind of communication activities, students master basic language knowledge and skills, form correct attitudes and concepts, improve humanistic literacy, and cultivate cross-cultural communication skills in cross-cultural understanding, communication, and critical skills.

\subsection{Intercultural Communication in College English Teaching}

The word "communicate" is closely related to "commonality". The word communicative comes from the Latin word commonis. Obviously, the concept of communication is closely related to "commonness", that is, "common service" or "share" is the premise of communication; Moreover, effective communication can only take place if people of the same culture share in many ways. It can be seen that the connotation of "common" is consistent with the connotation of "communication" and "culture". This shows that communication is a communication in a common cultural context. And cross-cultural communication is "the process in which people with different cultural backgrounds engage in communication is crosscultural communication. "Intercultural communication has social, purposeful, two-way, and situational characteristics. The so-called sociality is the communicative activity in which a cross-cultural communication takes place in a certain society. Any communicative activity takes place in a certain social background. Different cultures of society provide us with the possibility of cross-cultural communication; The purpose is that cross-cultural communication is purposeful, not blind communication. Two-way communication is the communication between two people with different cultural backgrounds. A single person cannot communicate with each other. There are objects in the communication. Communication can only take place in the presence of objects. Scenarios are communication in a certain situation. The ultimate purpose of studying college English is to communicate in English, and this communication is a cross-cultural communication. This is because we communicate in English with people with different languages and cultural backgrounds. If we communicate with people with the same language and cultural background, there is no need to use English to communicate, and it is normal to use the mother tongue Communication, the current society is an open society, and foreign exchanges are increasingly frequent, so cross-cultural communication is essential.

College English teaching is cross-cultural communicative. College English teaching is the main way to cultivate intercultural communication talents. In college English teaching materials, many contents reflect Western culture. An important reason for these content settings is to improve the cultural literacy of college students and cultivate cross-cultural communication capabilities of college students. These contents are of great help for students to understand Western culture and improve cultural 
literacy. But these contents are not enough, because Western culture is a large category, and students cannot understand Western culture well in several texts. Therefore, teachers should pay attention to increasing the explanation of Western cultural background and the recommendation and provision of relevant materials when teaching, to guide students to read, and to improve their cultural literacy, cultivate students' cross-cultural understanding, communication, and critical skills so that they have the ability to communicate across cultures.

\section{Current Situation of College English Teaching Reform}

The first aspect: the achievements of college English teaching reform.

Through a brief review of the course of college English teaching reform, we can see that the Ministry of Education attaches great importance to the reform of college English teaching. Under the guidance of the Ministry of Education and education departments at all levels, the vast number of teachers and students in various institutions of higher learning throughout the country have invested in the tide of reform with great enthusiasm. With the joint efforts of all parties, China's college English teaching reform has achieved staged results, and has been reformed in varying degrees in highlighting the development of listening and speaking skills and developing computer and classroom-based English teaching models. Great results have been achieved and a new situation has emerged. [8-10]

First, in accordance with the spirit of "University English Curriculum Teaching Requirements", in accordance with its own characteristics and reality, universities and colleges are actively building "computer-based and classroom-based English teaching models" to explore different modes of combining classroom teaching with computer networks and autonomous learning.

Secondly, college English teaching has received more and more support from various departments and its status has been significantly improved. This is manifested in the financial investment in college English software and hardware construction by schools and departments at all levels.

Thirdly, the teaching evaluation system, as an important part of the reform of college English teaching, has also been greatly developed, and many colleges have adopted the method of multiple evaluations.

The second aspect: the problems of college English teaching reform

Although the current reform of college English teaching in China has achieved gratifying results, greatly promoted the development of college English education, and provided favorable conditions for the cultivation of English talents, it is undeniable that there are still certain reforms in the reform. There are many problems that need to be further deepened and improved.

First, many colleges and teachers lack a correct understanding and understanding of the new college English teaching model.

Secondly, in terms of curriculum setting, although colleges and universities have implemented classbased grading teaching according to the situation, relevant experts have pointed out through investigation that "the curriculum design is unscientific in the curriculum arrangement and the training of listening, speaking, reading and writing skills. "The curriculum is not standardized, there are obvious regional differences, the effect of the reform is still unsatisfactory, and the students' practical ability to use English still cannot meet the needs of society."

Thirdly, although most colleges and universities have implemented evaluation methods that combine formative and summative evaluations, "foreign language teaching evaluation lacks scientificity", "currently the evaluation structure of college English is not reasonable enough, and the operation does not meet the evaluation requirements. It is necessary to build a scientific evaluation system based on the principles of evaluation."

It can be seen that the current reform of college English teaching needs further exploration and practice in terms of curriculum settings, teaching models, and evaluation systems. But no matter which aspect of the problem, the reason is largely due to the changes in the relationship between teaching and learning, teachers and students, caused by information technology such as computer multimedia entering college English. Changes in models, assessment systems, and even teaching concepts. In order to make full use of modern information technology for the teaching and reform of college English, a large number of experts and scholars have provided suggestions and suggestions, among which there are many discussions and even arguments on some issues. However, no matter which side of the argument, no 
matter which method of teaching in the past. As far as the current status of college English teaching in China is concerned, the relationship between information technology with computer network as the core and college English teaching cannot be well handled, and the organic combination mode of the two cannot be explored. In this context of social environment and history, this article attempts to reexamine college English teaching from a new perspective, and examines what changes have taken place in college English after information technology has entered college English teaching, and how to teach and teach in the new environment. The organic combination of learning, how to deal with the relationship between teachers and students, how to build a teaching mode that combines information technology with the classroom, and how to establish an ecological environment suitable for college English teaching.

\section{The Ways for Teachers to Create Students' Courses Independently from the Perspective of Innovation}

At present, the degree of autonomy of college English teachers is not high, and the ability of autonomous curriculum creation is not optimistic. In view of this, how will individual teachers and organizational management departments effectively improve their ability to implement courses? In this chapter, we will elaborate on how to improve teachers' ability to create their own curriculum. Take this as a side realization of our reform plan.

\subsection{Understanding the Course Accurately}

Ideas affect behavior, and behavior reflects ideas. In the course implementation, the premise for teachers to scientifically and rationally break through routines is to accurately grasp and understand the curriculum. If the course is not accurately understood by the teacher, or is misunderstood or even misunderstood by the teacher, then course experts and decision-makers devote great efforts to elaborate and package the ideal course or official formal course, which is difficult to achieve the intended purpose, or even seriously deviate from the intended purpose. Only when teachers take the initiative to accurately understand the curriculum can they become conscious practitioners and creative builders of the curriculum. [11] Teachers' accurate understanding of the curriculum and its transformation into curriculum behaviors are a very important part of the process of teachers transforming cognitive curriculums into realistic educational power.

If college English teachers really want to realize their own subjective value and give play to their autonomy and creativity in curriculum implementation. The first way to conduct independent curriculum creation is to establish a strong curriculum awareness, accurately understand and grasp the formal curriculum in the form of definitive solid texts such as unified requirements, outlines, plans, and prescriptive textbooks. The macro curriculum and cognitive level curriculum consciousness and concepts are integrated into their daily college English teaching practice, and their own curriculum concepts are enriched from daily teaching to integrate curriculum and teaching.

College English teachers are engaged in basic teaching in colleges and universities. Most of the time, they only think about how to increase students' knowledge of English and improve their ability to use English. That is to say, they pay more attention to teaching problems, but have less conscious rational thinking on some curriculum problems. Teachers with strong curriculum consciousness always maintain a high degree of sensitivity and consciousness to the courses they teach, and are no longer limited to a unified fixed textbook. Instead, always pay attention to the curriculum materials and information that are in line with the curriculum requirements, social requirements and student needs, and flexibly conduct secondary development of the teaching materials. Make full use of various curriculum resources other than teaching materials to provide a variety of possible platforms for the realization of curriculum value, the comprehensive development of students and their own growth.

\subsection{Flexible Creation Course}

After the teacher understands the curriculum accurately, and after organically integrating the relationship between the curriculum and teaching, the teacher has a strong curriculum awareness. 
Curriculum consciousness should ultimately be reflected in daily course implementation behaviors. To effectively transform curriculum awareness into specific teaching behaviors, teachers need to exercise their autonomy. Creatively generate your own unique teaching goals and flexible, open teaching plans in all aspects of course implementation. At the same time, the secondary development of teaching materials, flexible reconstruction of teaching content, and implementation of diverse teaching organization methods.

Teachers' independent creation of curriculum goals during curriculum implementation means that teachers adapt, transcend, and creatively modify, supplement, expand, and extend curriculum presets, certainties, and rigid goals. Personalize the target twice as if the actor were to the script. College English teachers exert their autonomy in the implementation of the curriculum, pursue the organic combination of knowledge and skills, processes and methods and emotional, attitude, and value values to carry out meaningful curriculum creation, which has very important curriculum value and significance. In this process of creation, the two main teaching subjects, teachers and students, in terms of knowledge and ability, emotional attitude. It is still enriched, improved, and matured in terms of experience (or experience) and values, and promotes the teaching growth, teacher and student growth and development together.

The first step in implementing the course is to determine what to teach, because the course content is a necessary condition for the successful completion of the course goals. Is it done in strict accordance with the prescribed teaching materials in order to complete the teaching tasks? Or do you have to shake everything you know to students according to your hobbies or specialties? We still have to listen to the students' arrangements. What teachers do they want to listen to? If the teacher teaches in strict accordance with the preset content of the prescribed textbook, then the teacher is "teaching textbook" instead of "teaching with textbook". Teachers have no autonomy and creativity is wiped out. If the teacher implements the teaching of the curriculum in accordance with his own interests, the teaching will inevitably be blind and systematic; If the teacher gives full play to the student's autonomy, the student will teach whatever he wants, and let the student take the initiative, then the teaching will lack science, because what the student wants to learn may not exactly match what the student should or must learn. During the upward climbing stage, due to the lack of a higher height and a wider field of vision, students cannot really see higher and farther. Some of the needs of the students are one-sided, narrow, and even deviated. Ground butt. Therefore, "Mr." must be well guided. The so-called "sir" means that the students must experience it first. Therefore, in order to solve the question of what should be taught, what can be taught, what needs to be taught and answered in the course of implementation, teachers need to give full play to their autonomy, so that the content of the course is not only scientific, but also flexible and creative. Therefore, the important content of teachers' selfinitiated curriculum creation in curriculum implementation is the secondary development of the determined and prescribed teaching material content.

After creating his own personalized teaching goals under the consciousness of autonomous curriculum creation, and creatively reconstructing the teaching content based on a unified textbook, the key question for teachers to consider is what methods, methods and methods to organize The teaching content and teaching experience have been selected, adapted or independently created to meet national requirements and preset goals. Is the content "Yitangtang" out of the ground? Or design heuristic questions or organize interactive discussions to guide students to actively participate in the classroom, actively explore knowledge, and improve their ability autonomously? A creative teacher is always good at thinking autonomously how to adopt flexible and diverse ways and means to present content, so as to stimulate the enthusiasm and initiative of students, guide students to think independently, analyze problems and solve problems. Instead of simply injecting ducks to obtain students' mechanical memory and passive acceptance of knowledge, emphasis is given to light inspiration. Teachers can pay attention to mobilizing their own wisdom in the following links, and work hard on skills and artistry to achieve autonomous creation of curriculum implementation.

Autonomous and creative teachers also pay great attention to the cultivation and use of their teaching wit, and can spontaneously turn incidental course events into generative course resources in teaching practice. Often faced with new problem situations, they can quickly make accurate judgments and take appropriate real-time actions to subtly change teaching "crisis" into teaching "opportunity". Teachers with a strong ability to respond to teaching "can sense sharply, accurately judge new situations and problems that may arise in the process of generation and change, and have the tact to grasp 
educational opportunities and transform educational contradictions and conflicts; It has the charm of making decisions and choices in a timely manner according to the actual situation of the subject and the adjustment of educational behaviors... "In a timely and sensitive manner, it is transformed into a generative curriculum resource. [12]

In the era of advocating innovation, modern teachers must also have the educational concepts and knowledge of independent innovation, and be able to consciously transform this knowledge into abilities, which are then fully reflected in teaching behavior. Autonomous and creative teachers will not "speak out" and will flexibly control the relaxation of "teaching" and "discussion". Teachers who talk from beginning to end of a lesson will not effectively organize classroom activities, and the classroom will become the teacher's solo stage. Teachers should change from simply teaching or explaining knowledge to working with students to apply knowledge, perform tasks, or carry out activities. In addition to this requirement, teachers must have the ability to use foreign languages, and more importantly, the ability to guide students to use foreign languages. The best way to guide students to apply foreign languages is to let students develop their application skills in the application. This needs to provide students with the opportunity and environment to apply foreign languages, depending on the design of activities or tasks to apply foreign languages. These activities or tasks play an important role in stimulating students to think independently, analyze problems, solve problems, and release students 'creativity. They are also the most difficult part for teachers to master, but they are also the ones that can best reflect teachers' independent creativity. Giving full play to students' autonomy does not mean that students are in a state of free discussion and skirmish, nor is it left to students to blindly touch and roll after the task is arranged or after the activities are carried out, and complete it by themselves. The effective display of student autonomy is inseparable from the process of effective classroom activities organized by teachers. Autonomous and creative teachers will effectively combine "teaching" and "discussion", and observe carefully in class discussions or debates, inspire and guide in a timely manner, and participate in the whole process, not only fostering outstanding students to actively discuss, but also encourage students with learning difficulties to participate actively In order to motivate all kinds of students. After the discussion, the teacher's autonomy is more reflected in the real-time induction and summary of the students 'difficulties and doubts according to the on-site discussions in order to advance the students' level of knowledge to a higher level.

Teaching evaluation is an indispensable link for teachers in the implementation of curriculum teaching activities. It plays an overall role in regulating and directing teaching activities to ensure that teaching activities reach the intended goals. In addition to being able to test the teaching effect, it can also diagnose teaching problems in time, so that teachers can adjust teaching strategies in a timely manner, improve teaching measures, and solve teaching problems. At the same time, it can also provide feedback information for teachers and students to guide the direction of teaching and control the teaching process. When teachers play the role of classroom evaluation, they also need to focus on tapping and developing the potential of students' self-evaluation. Actively guide students to participate in classroom assessments, adopt mutual assessment and self-assessment, and encourage students to think independently. It evaluates both the learning materials and its own learning process, as well as the teachers' teaching methods and means.

\subsection{Continuous Reflection Course}

Teachers' curriculum reflection is actually the teacher's internal and external thinking exchange and communication. The internal thinking exchange means that the teacher must conduct a deep examination and analysis of a series of teaching problems in his own teaching practice. External thinking exchange refers to the teacher's in-depth understanding and digestion of curriculum ideas, concepts, behaviors, and strategies of relevant participants (such as curriculum experts, teaching managers, textbook writers, colleagues, and students) during the course implementation. Without digestion, there is no metabolism. Only through reflection can breakthroughs and transcendences be achieved and innovations be achieved.

Reflection is a mirror that enables teachers to rationally judge the appropriateness of curriculum policies, face up to curriculum and teaching problems, analyze the causes of problems, and find solutions to problems. Therefore, in the implementation of the curriculum, teachers' efforts to improve their 
critical reflection ability are not only the reflection at the conscious level, but more importantly, the reflection into reality. Teachers' group reflections include:

1) Sharing of practical experience. This kind of practical experience sharing can be the exchange and sharing among teachers in the school, or the sharing activities among the peer teachers across the school. It can be written teaching and research paper exchanges, or oral experience and experience. This sharing of experience can motivate teachers to think about common problems in the process of curriculum creation, and think about solutions together. At present, the sharing of practical experience in schools can be carried out regularly or indefinitely during the teaching activities of teaching and research groups,

2) Expert guidance and dialogue. You can communicate with peer experts in two ways: "Please come in" and "Go out." Periodically or irregularly, please invite course experts or teaching teachers to come to your school or classroom to observe and discuss with them after class. Teachers can also seize almost or try to create opportunities to take the initiative to go to other schools, enter expert classrooms, observe in close class, and discuss together, so as to improve their own understanding, resolve confusion, and improve their ability to create courses.

\subsection{Active Learning and Autonomous Inquiry}

An important aspect of the connotation structure of the concept of teacher autonomy is the enterprising nature of the teacher, which shows that the teacher actively learns and pursues a higher spirit of exploration. This is the process for teachers to pursue their own professional growth. Without a proactive learning spirit, you cannot keep up with the times, your stagnation will stagnate, and your creativity will gradually shrink, and the creation of courses in teaching practice will become empty talk. Active learning, strengthening cooperation, and improving together are the inexhaustible source and inherent motivation for teachers to improve their ability to create autonomous courses. It can be seen from the survey that at present, college English teachers have shown a high enthusiasm for learning, especially young assistants and lecturers in marginal second-class colleges. However, most of the learning needs are based on instrumental motivation and meet the academic and degree requirements for professional title evaluation. At the same time, there is no rational thinking about what to learn or how to improve one's teaching ability through learning. From the perspective of the influencing factors of curriculum creation ability, many teachers have also reflected that they also want to give play to their autonomy in curriculum practice and realize their own subjective value. But suffering from oneself does not create students, I do not know how to create students, and I do not know exactly what can be learned to improve my curriculum creation ability.

It can be seen that the factors affecting teachers' initiative and creativity are individual teachers and environmental factors. As an individual teacher, establishing the concept of curriculum creation is the first step, and then we can talk about behavioral innovation. Through in-depth understanding of the relationship between the curriculum and teaching, establish a strong curriculum awareness to accurately understand the curriculum, realize the unity of the college English curriculum requirements and the actual connection of their own personalized teaching. Pay attention to the harmonious unification of single and multiple goals, strategic goals and tactical goals, static preset goals and dynamically generated goals, precise goals and flexible goals in the course teaching. Only after creating actual and characteristic course teaching goals can students have innovative course teaching content. In terms of the creation of the teaching content of the course, special attention was paid to the secondary development of the teaching materials. Pay attention to targeted selection and adaptive adjustment of textbook content, cultural criticism and reconstruction of textbook content, development of highly lifelike and social content in the student's living world, and creative critique and use of teacher reference materials. In terms of the implementation of the curriculum, teachers need to actively think about the way of introducing the content of the curriculum, the effective creation of teaching situations, the way of setting up classroom questions, teaching examples, the on-the-spot response to classroom emergencies, the setting and handling of homework assignments, and the flexibility Design and organization of classroom activities and multi-teaching evaluation. The key to improving the initiative and creativity of the curriculum is that teachers should develop the awareness and habit of continuous reflection. Teachers can reflect on pre- and post-class reflections by writing teaching reflection diaries, classroom videos, or compiling teaching reflection self-assessment forms. They can also reflect on group practical experience sharing, expert interaction, and topic discussions. 


\section{Conclusion}

This study is based on the era of English education reform and pays close attention to the latest policy information of the country. Investigation and analysis from students, society, colleges and universities, and other aspects, trying to provide a feasible reform plan for college English teaching reform. This study does not discuss the curriculum and the arrangement of class hours in the same way as previous studies. Instead, we seek breakthroughs from the interpretation of improving and improving English teachers. I hope that this research result can effectively improve the quality of English teachers and make them feel their mission and urgency. It is hoped that the majority of front-line English teachers can break through the constraints, make bold innovations, and train more comprehensive English talents, instead of simply manufacturing examination machines. The smooth implementation of the research results depends on the strong support of society, especially the national education authority, and the sufficient freedom given to teachers. If the competent department can trust the teacher from the source and give the classroom control right to the teacher completely, then the teacher can let go of the burden and make bold innovations. If you do not break, you do not stand.

All members of this research group are composed of front-line university English teachers, although they have great advantages in analysis teaching and curriculum. But lack of understanding, analysis and design of policy guidelines, and failed to get in touch with the government and management during the research process. It is possible that many details need to be improved in the actual implementation of the research results.

Acknowledgements. This paper is supported by the Henan Social Science Federation Project (SKL$2019-2208)$.

\section{References}

1. Wang P Y, Yang H C (2012), "Using collaborative filtering to support college students' use of online forum for English learning," Computers \& Education, vol. 59, no. 2, pp. 628-637.

2. Lamb M (2012), "A self system perspective on young adolescents' motivation to learn English in urban and rural settings," Language learning, vol. 62, no. 4, pp. 997-1023.

3. Ahmed M (2016), "The effect of a flipping classroom on writing skill in English as a foreign language and students' attitude towards flipping," US-China foreign language, vol. 14, no. 2, pp. 98-114.

4. Aljumah F H (2012), "Saudi learner perceptions and attitudes towards the use of blogs in teaching English writing course for EFL majors at Qassim University," English language teaching, vol. 5, no. 1, pp. 100-116.

5. Al-Issa A S, Al-Bulushi A H (2012), "English language teaching reform in Sultanate of Oman: The case of theory and practice disparity," Educational research for policy and practice, vol. 11, no. 2, pp. 141-176.

6. Wenhong H (2016), "Study on college English teaching mode multimedia assisted based on computer platform," International journal of multimedia and ubiquitous engineering, vol. 11, no. 7, pp. 351-360.

7. Tong F, Shi Q (2012), "Chinese-English bilingual education in China: A case study of college science majors," International journal of bilingual education and bilingualism, vol. 15, no. 2, pp. 165-182.

8. Nguyen X N C M, Walkinshaw I (2018), "Autonomy in teaching practice: Insights from Vietnamese English language teachers trained in Inner-Circle countries," Teaching and teacher education, vol. 69, no. 3, pp. 21-32.

9. Tayan B M (2017), "The Saudi Tatweer education reforms: Implications of neoliberal thought to Saudi education policy," International education studies, vol. 10, no. 5, pp. 61-71.

10. Yeh Y L, Lan Y J (2018), "Fostering student autonomy in English learning through creations in a 3D virtual world," Educational Technology Research and Development, vol. 66, no. 3, pp. 693-708.

11. Jindapitak N (2019), "English as an ASEAN lingua franca and the role of nativeness in English education in Thailand: Moving toward the ASEAN Economic Community (AEC)," English today, vol. 35, no. 2, pp. 36-41.

12. Nurman K, Arsyad S (2019), "Discourse markers in argumentative essay by the English education study program's students of Universitas Bengkulu: A cross-sectional study," Journal of English education and teaching, vol. 3, no. 1, pp. 29-41. 